\section{Effective clinical conversations: the art of curiosity}

\author{
John Launer
}

For many years, I have worked with a team of educators who promote peer supervision among doctors and other health professionals. Our aim is not just to help people to become better supervisors, but to use peer supervision as a safe space for people to develop better interactional skills generally - and particularly to cultivate their curiosity. ${ }^{1}$ In every training we run, we use an exercise that involves dividing people into pairs and inviting one person in each pair to talk about something that is bugging them at work: a particular clinical case or a difficulty with another member of staff. We always emphasise that the exercise is not a role play but what is sometimes called 'real play.' The problems or dilemmas that are brought for supervision have to be current, unresolved and involve real individuals - who do not have to be named or identified. The role of the other person in each pair is to interview their partner and follow some very simple conversational rules (see box 1). We sometimes call these the golden rules. After twenty minutes or so, the two people change places so that the interviewer has a chance to become the 'client' and vice versa.

The exercise has pretty much the same effect every time. At first people think the three rules will be very simple to follow. Once they try to use them, however, they find this not the case. They discover all kinds of ingrained conversational habits that get in the way. These include the urge to give advice, or at least to suggest this by their questions ('have you thought of...') Other typical habits include offering information that has not been requested, changing the subject to themselves and their own experiences, offering reassurance all the time, or reframing everything the person has said in their own words ('it sounds to me as if...). They find themselves asking questions that are long and convoluted, or sound repetitive and formulaic ('how did you feel about that?). Some people cannot stop reflecting back almost every phrase or sentence ('so what

Correspondence to Dr John Launer, Associate Editor, Postgraduate Medical Journal, London, UK; johnlauner@aol.com you're saying is...'), or making interpretations ('I suspect what is really going on here...').

Of course, some of these forms of speech can be useful in many circumstances. The problem is that for many people they have become unreflective. They do not necessarily fit the moment or the person they are speaking to. The point of the exercise is not to eradicate these habits entirely but to make people aware of their automatic ways of interacting with others, and to make better choices about whether, when and how to apply these. To do this, they may first need to pare down our conversations, at least initially, to a stance of pure curiosity. That is what the exercise is designed to achieve.

\section{SPEAKING IN ORDER TO LISTEN}

The three rules of our exercise are not random. They are based on the work of four Italian psychiatrists known as the Milan Team. Around forty years ago, they examined their interventions in clinical conversations with patients and their families to find out what seemed to be effective. They derived three principles that they called 'hypothesising', 'circularity' and 'neutrality'. 2 The concepts are each quite simple. Hypothesising describes the ability to frame ideas in your own mind in order to generate good hypothesis-testing questions, but not to pursue them if they prove unfruitful or seem to have no traction with the other person. The principle of circularity depends on allowing your own speech to be guided by the other person's narrative and not vice versa. One therapist has aptly described this as 'speaking in order to listen' and not 'listening in order to speak'. ${ }^{3}$

Neutrality is close to what is sometimes called equipoise or equanimity - the capacity not to impose your own views

\section{Box 1 The three golden rules}

1. Only ask questions: keep them short

2. Link each question with something the other person has said.

3. Try to withhold advice, suggestions or interpretations as much as possible. and simple. or feelings on someone else unless you think your professional role absolutely requires this. Later, one member of the team, Gianfranco Cecchin, wrote a further paper arguing that all therapeutic conversations were in fact based on one quality only: curiosity. ${ }^{4}$ The golden rules of our exercise correspond nicely with their three principles, a well as their emphasis on curiosity.

The golden rules also share some common ground with other approaches including coaching and counselling. They are in a sense a distillation of these. Some clinicians who practise the approach over time say that their work has become faster and less stressful. Rather than opening up a Pandora's box by their questioning, as they might have feared, they realise they are now more attuned to what others are saying and hence get the gist more quickly. They are also better at facilitating change in others without feeling the need to nudge or prod them. Once people discover how some of their conversational habits interfere with effective dialogue, they may find this transforms their way of working. In the words of one learner, 'I have been liberated from the role of Dr Fixit.' With surprising frequency, people who have learnt the approach in the context of peer supervision report using it right across the board, including with patients, and even with family and friends.

\section{DEFAULT POSITION}

The idea that curiosity alone is the most powerful ingredient in conversations is hard for some to accept. A frequent objection is to point out that people who come to us with problems are implicitly asking for information, advice and solutions and not just wanting us to be curious. This is true but misses the point in a number of ways. For one thing, some people come for other purposes that we may fail to notice, such as offloading, or trying to work out their best options for themselves without needing to hear our views. Even when they ask for guidance directly, they may still find it more helpful if you ask questions first in order to pitch this appropriately. The rule to withhold advice, suggestions and interpretations is not an absolute ban but is simply a caution not to impose these without considering whether they are wanted or needed, or might at least be delayed until later. Applied properly, the rules are not meant to lead to an inquisition or to be used inflexibly on all occasions. They 


\section{On reflection}

are intended first as a learning exercise, and then to be available as default position whenever they might be helpful. Try them out, and you may be surprised how often curiosity alone achieves what all our other tendencies like giving advice or reassurance cannot.

Twitter John Launer @JohnLauner

Funding The authors have not declared a specific grant for this research from any funding agency in the public, commercial or not-for-profit sectors.
Competing interests None declared.

Patient consent for publication Not required.

Provenance and peer review Not commissioned; internally peer reviewed.

(C) Author(s) (or their employer(s)) 2021. No commercial re-use. See rights and permissions. Published by BMJ.

\section{Check for updates}

To cite Launer J. Postgrad Med J 2021;97:339-340.

Postgrad Med J 2021;97:339-340. doi:10.1136/postgradmedj-2021-140098
ORCID iD

John Launer http://orcid.org/0000-0003-3833-9352

\section{REFERENCES}

1 Conversations Inviting Change. Available: www.conv ersationsinvitingchange.com [Accessed 1 Mar 2021].

2 Selvini MP, Boscolo L, Cecchin G, et al. Hypothesizing-circularity--neutrality: three guidelines for the conductor of the session. Fam Process 1980;19:3-12.

3 Shawver L. If Wittgenstein and Lyotard could talk with Jack and Jill: towards postmodern family therapy. J Fam Ther 2001;23:232-52.

4 Cecchin G. Hypothesizing, circularity, and neutrality revisited: an invitation to curiosity. Fam Process 1987;26:405-13. 